\title{
A Case Report: Symptomatic Sacral Tarlov Cyst in a Male of 24 Years
}

\author{
Quadrat-A-Eahsan Ullah ${ }^{1}$, Muhammad Awlad Hussain², Abu Sayed ${ }^{3}$, Mohammad Abdul Quader ${ }^{4}$
}

\begin{abstract}
Perineural (Tarlov) cyst, a rare but benign condition, is meningeal dilatations of the posterior spinal nerve root sheath that most often affects sacral roots and can cause a progressive painful radiculopathy. Tarlov cysts are most commonly diagnosed by lumbosacral magnetic resonance imaging (MRI) and can often be demonstrated by computerized tomography (CT) to communicate with the spinal subarachnoid space. The cyst can enlarge via a net inflow of cerebrospinal fluid, eventually causing symptoms by distorting, compressing, or stretching adjacent nerve roots. It is generally agreed that asymptomatic Tarlov cysts do not require treatment. When symptomatic, the potential surgery-related benefit and the specific surgical intervention remain controversial. A 24 years old male presented with a history of trauma and pain in his low back with dull headache for six months. Physical and radiographic examination was consistent with tarlov cyst. Microsurgical excision with plication of the cyst wall was performed. Histo-pathological examination confirmed the diagnosis of Tarlov cyst. Excellent clinical and functional results were obtained with no recurrence after 6 months of follow-up. Tarlov cyst in a male of age 24 is a rare entity and decision making for management poses difficulties. Our experience with microsurgical excision with plication of the cyst wall was quite satisfactory with excellent clinical result, and we recommend this as one of the satisfactory modalities of treatment of Tarlov cyst in adult. Keywords: Tarlov cyst; perineural cyst; sacral region; microsurgical excision; cyst wall plication.
\end{abstract}

Delta Med Col J. Jul 2017;5(2):99 - 103

\section{Introduction}

Tarlov cysts were first described by neurologist Isadore Tarlov, in 1938 as an incidental finding at autopsy. ${ }^{1}$ Tarlov described a case of symptomatic perineural cyst and recommended its removal. Since then a few cases have been reported in the literature. ${ }^{2-4}$ Paulsen reported the incidence of Tarlov cysts as $4.6 \%$ in back pain patients.
Only $1 \%$ of back pain patients were symptomatic. ${ }^{4}$ The patient may present with low back pain, sciatica, coccydynia or cauda equina syndrome. The cysts are usually diagnosed on MRI, which reveals the lesion arising from the sacral nerve root near the dorsal root ganglion. ${ }^{5}$ Tarlov advised extensive surgery with sacral laminectomy and

1. Registrar, Dept. of Orthopaedic Surgery, Delta Medical College, Dhaka, Bangladesh.

2. Jr. Consultant, OSD, DGHS, Dhaka, Bangladesh.

3. Associate Professor \& Head, Dept. of Neuro Surgery, Sir Salimullah Medical College, Dhaka, Bangladesh.

4. Professor \& Head, Dept. of Orthopaedic Surgery, Delta Medical College, Dhaka, Bangladesh.

Correspondence: Dr. Quadrat-A-Eahsan Ullah. e-mail: quadratsohana@gmail.com 
excision of the cyst along with the nerve root. ${ }^{6}$ Paulsen reported CT-guided percutaneous aspiration of these perineural cysts for relief of sciatica. ${ }^{4}$ Recently, microsurgical excision of the cyst has been advocated, combined with duroplasty or plication of the cyst wall. ${ }^{7}$

We report a case of symptomatic Tarlov cyst presenting with back pain, to increase the awareness of this rare entity in the orthopedic and neurosurgical community.

\section{Classification}

Tarlov cysts are considered Type II lesions, being defined as intradural meningeal cysts with nerve fibres. Nabors et al. classified arachnoid cysts into three types. ${ }^{6}$

\begin{tabular}{|c|c|}
\hline Stage & Description \\
\hline Type I & $\begin{array}{l}\text { - Extra-dural } \\
\text { - No nerve roots or rootlets such as intra-sacral meningoceles } \\
\text { - Probably of congenital origin developing from the dural sac to which they } \\
\text { are connected by a little collar } \\
\text { - Found at the point of exit of a dorsal nerve root from the dural sac } \\
\text { - Sometimes difficult to identify and can be seen as a type II cyst on } \\
\text { imaging } \\
\text { - Often associated with foramina enlargement and scalloping of the } \\
\text { vertebrae } \\
\text { - Often associated with other congenital abnormalities e.g. teratomes, } \\
\text { dermoides, lipomes, and other abnormalities (uro-genital and ano-rectal) }\end{array}$ \\
\hline Type II & $\begin{array}{l}\text { - Intra-dural } \\
\text { - Nerve roots are present on the wall } \\
\text { - There are often not only one but multiple cysts, mostly found in the } \\
\text { sacrum area } \\
\text { - There are two types: } \\
\text { 1.Tarlov (perineural) cysts } \\
\text { - located posteriorly to the root ganglion, with nerve fibres inside or } \\
\text { nerve tissue in the walls } \\
\text { - communicating with the perineural arachnoid space } \\
\text { - Type-II cysts are very small in the upper sacral area, but can be bigger } \\
\text { (up to } 3 \text { centimetres or } 1.2 \text { inches) if found located in the lower part } \\
\text { of the sacrum. } \\
\text { 2.Meningeal diverticuli } \\
\text { - located anteriorly to the nerve root ganglion, with nerves fibres inside } \\
\text { and communicating with the subarachnoid space }\end{array}$ \\
\hline Type III & $\begin{array}{l}\text { - Intra-dural } \\
\text { - Either congenital or caused by trauma } \\
\text { - About } 75 \% \text { can be found in the dorsal area. Most of the congenital type- } \\
\text { III cysts can be found posteriorly to the spinal cord, as opposed to those } \\
\text { caused by trauma which can be found anteriorly to the spinal cord } \\
\text { - Post traumatic inflammation induces cavitation and cystic formation and } \\
\text { leads to greater secondary CNS injury }{ }^{8}\end{array}$ \\
\hline
\end{tabular}

\section{Case Report}

An Asian Muslim male of 24 years came to the department of Orthopaedics of Delta Medical College, Dhaka, Bangladesh with the history of low back trauma 6 months back followed by dull persistent low back pain (LBP), radiating to the buttock and back of thigh, with progressive tingling and numbness of the both lower limbs with more prominence on left side, aggravated by movement but not by coughing, sneezing or straining and relieved by taking rest and analgesics. For last one month patient developed mild frontal headache with no radiation, occasionally associated with nausea but no vomiting, more prominent at morning and decreased in the evening, aggravated by bending forward and relieved by lying down. There were no other systemic symptoms with negative family history.

All cranial nerves were intact with no signs of meningeal irritation. Patient had normal bulk and tone of the muscle for the both lower limbs with bilaterally absent ankle jerk. Straight leg raising (SLR) test of left lower limb is positive at $70^{\circ}$ and patient was unable to walk on toe tips. Sensory function along the S1 dermatome was lost. There was mild tenderness over the sacrum with mild restriction of all movements of the lumbo-sacral spine.

Radiology revealed straightened lumber curvature due to muscle spasm (Fig 1). MRI showed thecal sac indentation at L3-L4, L4-L5 levels due to posterior disc bulge and large Tarlov cyst at S1-S2 level of spinal canal. Marrow signal intensity appears normal on T1W1 and T2W1 (Fig 2).

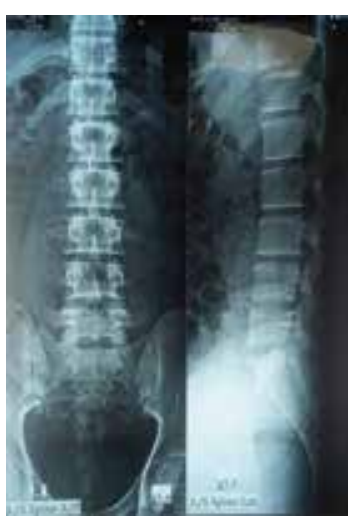

Fig 1: X-ray lumbo-sacral spine (A/P \& lateral view) showing straightening of the vertebra [Pre-operative] 


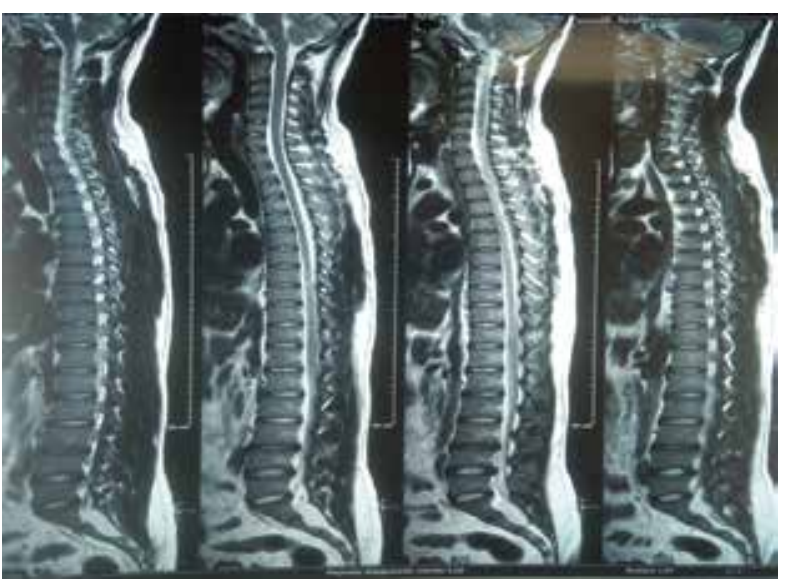

Fig 2: MRI of lumbo-sacral spine with screening of whole spine showing Tarlov cyst at $\mathrm{S} 1 \& \mathrm{~S} 2$ region (Red arrowed) [Pre-operative]

After sacral laminectomy, microsurgical cyst fenestration was performed. Briefly, after exposure of the L5-S1 sacral nerve roots, a large cyst was identified at S1 and S2 level of cord. The thin transparent cyst wall membrane was widely fenestrated with a scalpel and microscissors. A clear fluid content of the cyst was drained. Then cystectomy was performed with plication of the cyst wall. The wound was closed in layers.

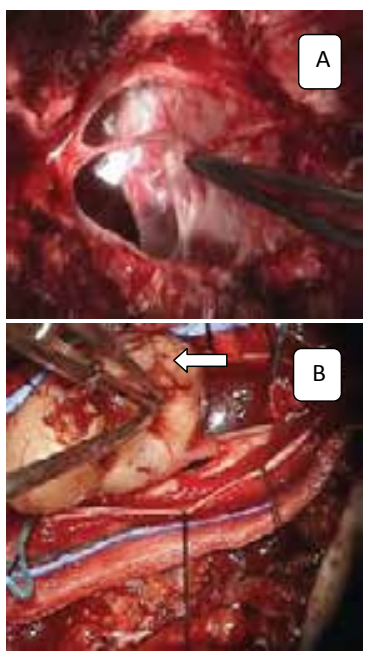

Fig 3: Different steps of operation

A- Fenestration \& Laminectomy

B- A large Tarlov cyst at S1 \& S2 level of cord (White arrowed)

C- Interior wall of the cyst having nerve roots (White arrowed)
Histopathology of specimen showed fibro -collagenous tissue with mild infiltration of inflammatory cells, area of haemorrhage and calcification. No evidence of malignancy is seen. Postoperative period was uneventful and the patient made prompt recovery. On two months follow-up, the patient had no pain in lower limbs and back. The patient returned to his previous job and now he is asymptomatic.

\section{Discussion}

Tarlov cysts are rare causes of low back pain. They are more common in females. ${ }^{4,7}$ Clinical presentation of Tarlov cysts is variable. The cysts may cause local and/or radicular pain. The dominant syndrome is referable to the caudal nerve roots, either sciatica, sacral or buttocks pain, vaginal or penile paraesthesia or sensory changes over the buttocks, perineal area and lower extremity. Depending on their location, size and relationship to the nerve roots, they may cause sensory disturbances or motor deficits to the point of bladder dysfunction. Tenderness on firm pressure over the sacrum may be present. Commonly, the symptomatology is intermittent at its onset and is most frequently exacerbated by standing, walking and coughing. Bed rest alleviates the discomfort. ${ }^{8}$

Plain X-rays are usually normal. However, they may reveal characteristic bone erosion of the spinal canal or anterior or posterior neural foramina. ${ }^{9}$ A CT scan can demonstrate cystic masses isodense with CSF located at the foramina. Bony changes may also be present. ${ }^{10}$ An MRI gives a much better soft tissue contrast and is currently the investigation of choice for perineural cysts. The cysts demonstrate low signal on T-1 weighted images and high signal on T-2 weighted images, similar to CSF. ${ }^{5}$ Myelography showing the filling of the meningocele sac $1 \mathrm{hr}$ after injection of contrast medium is highly suggestive of a perineural cyst. ${ }^{11}$ 
Microscopic features of the cyst were described by Tarlov. The early stage in cyst formation is that of a space between the arachnoid which covers the root or the perineurium and the outer layer of the pia cover of the root or the endoneurium. It usually begins in one portion of the circumference of the perineural space, the larger cysts compressing the nerve root to one side. The cyst occupies the posterior root abutting the proximal portion of the dorsal ganglion. Its main part is bordered by reticulum or by nerve fibers. ${ }^{1}$

The pathogenesis of perineural cysts is uncertain. Tarlov felt that hemorrhage into the subarachnoid space caused accumulations of red cells which impeded the drainage of the veins in the perineurium and epineurium, leading to rupture with subsequent cyst formation. Four out of the seven patients in Tarlov's 1970 article had a history of trauma. ${ }^{8}$ Schreiber and Haddad also supported this post-traumatic cause of cyst formation. ${ }^{12}$ Because many of the patients with perineural cyst in their series did not have histories of trauma, Fortuna et al. believed that the perineural cysts were congenital, caused by arachnoidal proliferations within the root sleeve. ${ }^{13}$ There is no consensus on a single method of treatment. Various methods have been advocated. Tarlov advised that symptomatic, single perineural cysts should be completely excised together with the posterior root and ganglion from which they arise. ${ }^{8}$ Paulsen reported CT-guided percutaneous aspiration of these perineural cysts in two patients for the relief of sciatica caused by compression. ${ }^{4}$ According to Caspar microsurgical excision of the cyst combined with duroplasty or plication of the cyst wall is an effective and safe treatment of symptomatic sacral cysts. The parent nerve root is always left intact. ${ }^{7}$
In our case, excellent clinical and functional results were obtained with microsurgical excision with plication of the cyst wall with no recurrence after 6 months follow-up.

\section{Conclusion}

Symptomatic Tarlov cyst is an uncommon entity. Proper diagnosis entails correlating the clinical presentation, anatomical location, radiological profile, and histopathological appearance. Microsurgical excision with plication of the cyst wall is a valuable treatment option.

\section{References}

1. Tarlov IM. Perineural Cysts of the Spinal Nerve Roots. Arch Neural Psychiatry. 1938;40(6):1067-74.

2. Chaiyabud P, Suwanpratheep K. Symptomatic Tarlov Cyst: Report and Review. J Med Assoc Thai. 2006;89:1047-50.

3. Acosta FL Jr, Quinones-Hinojosa A, Schmidt MH, Weinstein PR. Diagnosis and Management of Sacral Tarlov Cysts Case Report and Review of the Literature. Neurosurg Focus. 2003;15:E15.

4. Paulsen RD, Call GA, Murtagh FR. Prevalence and Percutaneous Drainage of Cysts of the Sacral Nerve Root Sheath (Tarlov cysts). AJNR Am J Neuroradiol. 1994;15:293-99.

5. Rodziewicz GS, Kaufman B, Spetzler RF. Diagnosis of Sacral Perineural Cysts by Nuclear Magnetic Resonance. Surg Neurol. 1984;22:50-52.

6. Tarlov IM. Cysts (Perineurial) of the Sacral Roots. J Am Med Assoc. 1948;138:740-44.

7. Caspar W, Papavero L, Nabhan A, Loew C, Ahlhelm F. Microsurgical Excision of Symptomatic Sacral Perineurial Cysts: A Study of 15 Cases. Surg Neurol. 2003;59:101-106. 
8. Tarlov IM. Spinal Perineurial and Meningeal Cysts. J Neural Neurosurg Psychiatry. 1970;33:833-43.

9. Taveras JM, Wood EH. Diagnostic Neuroradiology. 2nd ed. Vol 2. Baltimore: Williams and Wilkins; 1976. p. 1139-45.

10. Tabas JH, Deeb ZL. Diagnosis of Sacral Perineural Cysts by Computed Tomography. J Comput Tomogr. 1986;10:255-59.
11. Nishiura I, Koyama T, Handa J. Intrasacral Perineurial Cyst. Surg Neurol. 1985;23:265-69.

12. Schreiber F, Haddad B. Lumbar and Sacral Cysts Causing Pain. J Neurosurg. 1951;8:504-509.

13. Fortuna A, La Torre E, Ciappetta P. Arachnoid Diverticula: A Unitary Approach to Spinal Cysts Communicating with the Subarachnoid Space. Acta Neurochir (Wien). 1977;39:259-68. 